\title{
Local Cultural Spiritual Interpretation of the Logo Design of Large International Conference
}

\author{
Qing Wu, Xiaochao Sun
}

School of Art and Design, Wuhan University of Science and Technology, China

Keywords: International Conference; Logo Design; Local Culture; Interpretation.

\begin{abstract}
A systematic approach to the successful international conference logo based on local culture design is summarized. This article interprets logos containing the spirit of Chinese culture by the analysis of several logos of important international conferences recently held in China. Furthermore, people pursue local cultural origins of logo design. Meanwhile, we explore ways to incorporate indigenous culture and foreign culture and organically combine the traditional art and modern art in order to find out innovation expression methods of the logo design. The logo design of the international conference is complementary to the local culture, and the local culture is enriched and developed with the help of the conference logo.
\end{abstract}

\section{Introduction}

In recent years, many important international conferences have been held in China one after another. These international conferences have played a important role in promoting the inheritance, development, promotion, and spread of Chinese local culture. There is no doubt that the large-scale conference has erected a bridge for mutual communication and understanding between China and the rest of the world, and promoted the economic cooperation and cultural exchanges between countries, thus to promote the peace and development of the world. The sign of the major international conference should be paid specially attention. As we all known, the basic requirements of the logo design are beautiful, eye-catching, easy to identify, easy to remember, and the theme of the conference should be highlighted at the same time. Through the in-depth systematic study of the conference logo, we can find that they have deep origins with the local culture. Any international conference logo with local cultural connotation can leave unforgettable impression on people. For example, the emblem of the 2010 Shanghai World Expo was shaped by the Chinese character "shi". Please see figure 1.

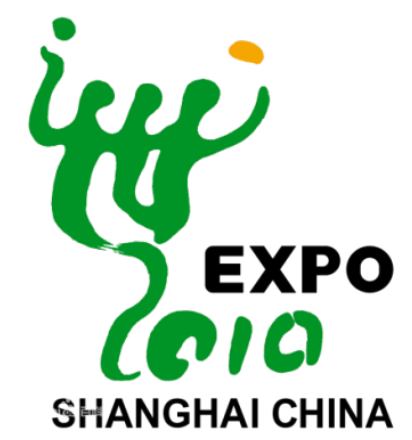

Fig. 1 Logo of 2010 Shanghai World Expo

The shape of "shi" implies that three people embrace each other by arms, which expresses the concept of "comprehension, communication, gathering and cooperation" of the World Expo. This logo not only highlights the theme of the conference, but also uses Chinese characters calligraphy to demonstrate the charm of Chinese local culture and at the same time fully embodies the generosity of Shanghai, the international metropolis to host the expo. Although the audience of large international conferences logo is all over the world, the people of different culture background can understand and communicate with each other by aid of the symbolic language of the logo. Obviously the conference 
logo is a symbol of cultural exchanges and also a link between the host country and participating countries. The prominent features of the large-scale conferences are focusing property and radioactivity. Along with large international conferences, various kinds of information have gathered from all sides to the conference, which have attracted the attention of the world. Different cultures will produce collisions and conflicts and massive amounts of information will also radiate to all over the world. Obviously the information will radiate the local culture and the conference spirit to the world. The conference logo is such a unique carrier of information transmission. Therefore, in the era of information globalization, the logo design of international conferences is of great significance to the spread and communication of information in society. It is very necessary to interpret the logos of international conferences profoundly. Several influential conference logos are explained below to pursue the cultural origin of the conference logo design and explore the system innovation method of conference logo design.

\section{Spread the national spirit of the Chinese dream based on the local culture}

In the 2017 Beijing Design Week, Xie Jianjun, Chairman of Dongdao Brand Creative Group Co., Ltd. made a statement of "image design of global summit". He made a wonderful interpretation of the international conference logo designed by the Dongdao company, which made people suddenly enlightened. The reason for the success of the design by Dongdao group is firstly based on the local culture to deeply dig the essence of the local culture instead of superficially using traditional cultural symbols to cobble together symbols. The logo designed by Dongdao reflects the national spirit and demonstrates the charm of the local culture. They use the rich local culture and colorful ethnic art as the creation source to design the logo to look for the inspiration for logo design from it. The G20 summit was held in Hangzhou in September 2016. As the main platform for global economic cooperation, G20 is an opportunity for China to develop the economy and promote the local culture. China is the largest developing country in modern times and a representative of emerging market countries. By hosting the G20 summit, China can make a speech on behalf of developing countries and achieve the benign interaction with more countries by "One Belt and One Road" and the Asian Investment Bank to achieve win-win cooperation with other countries. The settlement of the international summit in Hangzhou will drive the development of local infrastructure, promote the development of the local export-oriented economy, and increase the international level of Hangzhou. With this golden opportunity, Hangzhou can demonstrate to the world her heavenly beauty and unique local culture. In the design of the conference logo, the designer used the ancient legend "White Snake".

In the story, White Snake and Xu Xian met at the broken bridge in the West Lake and interpreted the love masterpiece that spreads through the ages. The designer used a modern curve to reinterpret the traditional culture and used 20 lines to depict a bridge-shaped silhouette. The bridge-shaped silhouette was based on the broken bridge in West Lake, which made people reminiscent of the romantic love story of the White snake and Xu Xian. And now the bridge symbolizes that the G20 has become a bridge for global economic growth, a bridge for international community cooperation, and a bridge for future win-win. At the same time, the bridge shape is similar to fiber optics, meaning the interconnection of the information age. The "line bridge" of the G20 in this logo pattern reflects the spirit of solidarity and cooperation among nations. At the same time the logo was supplemented by "G20 2016 CHINA" and the seal cutting clerical script "中国" seal. The Chinese seal highlights the connotation of Chinese traditional culture and echoes with English "CHINA". The logo uses modern artistic expression techniques. The main body is 20 curves, together with letters and numbers. The overall is fashionable and concise, which not only highlights the local characteristic culture of Broken Bridge in West Lake, Hangzhou, but also has a simple and generous style of the modern design. Please see figure 2.

The One Belt One Road Summit was held in Beijing in May 2017. Chairman Xi Jinping fully explained the purpose of the conference, which was to build the "One Belt and One Road" into a road of peace, a road of prosperity, a road of open, a road of innovation, and a road of civilization. The new 
type of international relations centered on win-win cooperation will be built industriously to create the partnerships where the dialogue is carried out without confrontation and companionships are formed without ally. We should focus on the fundamental issue of development, solidly promote the construction of economic corridors, and deepen interconnection and industrial cooperation, and improve the financial security system. An open cooperation platform should be built and the economic globalization that is open, comprehensive, inclusive, balanced, and win-win should be built. The innovation to drive development and green development should be adhered to, the multi-level humanistic cooperation mechanism should be established, more people's livelihood projects should be built, and the social inclusive development should be promoted. In order to publicize the theme of the conference, the conference logo uses gold and blue ribbons to represent the "Silk Road Economic Belt" and "21st Century Maritime Silk Road", supplemented by red, blue, brown, white and black color elements, which not only reflects the diversity of the "Belt and Road" culture, but also has Chinese characteristics. The two ribbons converge to form a ball type, which embodies the allegory of tolerance, unity and cooperation, and represents the human destiny community of global cooperation and mutual benefit. At the same time, the ribbon constitutes the English letter "S", which stands for silk. The spherical center is implied by the Big Wild Goose Pagoda, which means that the Silk Road takes China as the center, starts from Xi'an and benefits the world. Below the ribbon, the English abbreviation "BRF" is embedded in the summit forum to highlight the name of the conference. Please see figure 3. This logo uses two ribbons to create a dynamic $\mathrm{S}$, and the whole constitutes a spherical shape again with a strong contrast of colors, dynamics, and complete composition.
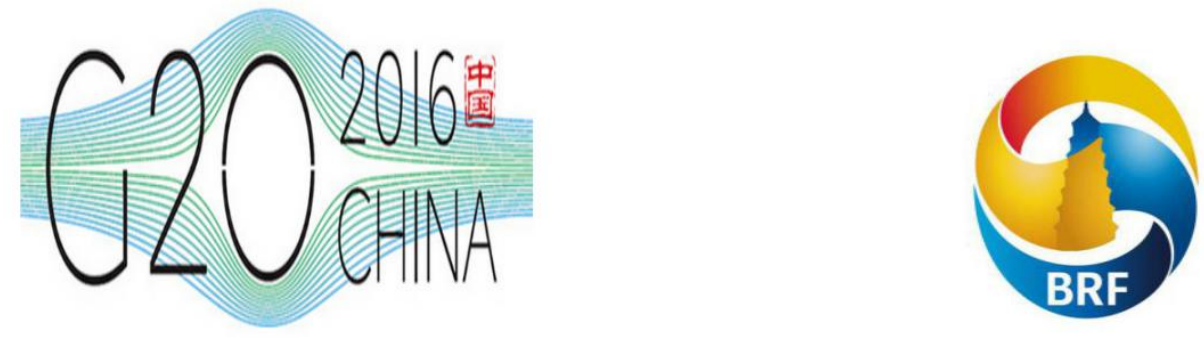

Fig. 2 G20 summit logo of 2016

Fig. 3 One Belt and One Road summit forum of 2017

\section{Integrate traditional art with technique of expression of modern design}

The requirements of the international conference design are very high, which not only carries forward the national spirit of China, reflects the realm of the world, but also expresses the spirit of the times. Therefore, the logo of an international conference should be international and fashionable. The use of modern design techniques and the use of a simple combination of geometric shapes illustrate the theme of the various conferences, reflecting the characteristics of the host place, which makes the logo of the conference full of flavors of the times and local characteristics. The local cultural elements are reconstructed by the techniques of modern art flexibly and the expression form conforms to the modern aesthetic taste. Resolving the contradiction between nationality and internationality shows that the Chinese people are fulfilling the development concepts of innovation, coordination, green, open, and share. Let the people of the world understand China more deeply through the logo of the conference to promote the exchanges and communication among people of all countries, further strengthen the economic and cultural exchanges and cooperation, achieve common development, and achieve win-win goals.

The 2019 Beijing World Horticultural Expo is scheduled to be held in Yanqing District, Beijing, China from April 29, 2019 to October 7, 2019. The expo is an A1 international horticultural exposition that is approved by the International Association of Horticultural Producers and authorized by the International Exhibitions Bureau. Please see figure 4. The logo of 2019 Beijing World Horticultural Exposition is six petals of different colors dancing around the Great Wall, vividly depicting the features of the International Horticultural Exposition at the foot of the Great 
Wall. The peace flower with three colors and six-petals bears the concept of Chinese philosophy of six directions. Six directions generally refer to heaven, earth, east, west, north and south, which symbolize heaven and earth or the universe, and symbolize the world peace, and express the desire to build a beautiful home that lives in harmony. The ingenious fusion of the pistil and the Great Wall is uniquely crafted. The combination of English, Pinyin and numbers indicates the name, time and location of the conference. The logo not only has the modern atmosphere but also has an internal Chinese context, which integrates spirit of the orient with modern science and art to fully embody the unity of nationalization and internationalization. The logo is full of vitality. Although it is a flat figure, it has a three-dimensional visual sense.

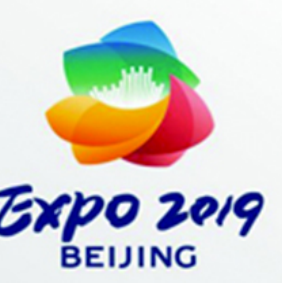

Fig. 4 The Expo logo for 2019

\section{The theme highlighted, innovative, simple and eye-catching}

In addition to highlighting the distinctive theme, the logo of the large international conference must also have the novel forms of expression. The Central and Eastern European Country Leaders' Meeting that echoes with the One Belt and One Road has had a great impact internationally. In 2013, a meeting of leaders from Central and Eastern Europe was held in Chongqing. The logo of the meeting is shown in figure 5 . The colors of bright red, yellow, blue and purple match each other. The concise and dynamic graphics are eye-catching. The first letters $\mathrm{C}$ and $\mathrm{Q}$ by Pinyin of Chongqing indicate that the host place is Chongqing. The logo as a whole can constitute an "e", which means that the information communication between various countries through internet is more quick and convenient. The information transferred by this logo is that the talk between leaders of various places will effectively promote the communication and exchanges between countries in Central and Eastern Europe, increase the friendship between countries, and enhance mutual economic and cultural exchanges.

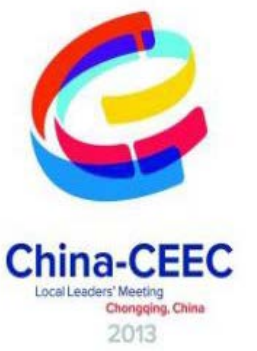

Figure 5: Logo of CEEC

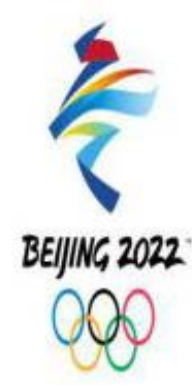

Figure 6: Logo of 2022 Winter Olympics in Beijing

The logo of the 2022 Beijing Winter Olympic Games is inspired by the Chinese character "dong". This logo is shown in figure 6.The upper part of the logo shows the shape of the skaters and the lower part shows the heroic posture of the skiers. The middle dancing line is smooth and rhythmic, which represents the rolling hills, stadiums, snow chute and dancing ribbons in the festival, which adds a festive visual perception to the logo and also symbolizes that the Beijing Olympic Winter Games will be held during the Chinese New Year. The logo of the whole Winter Olympic Games is concise and dynamic, reflecting the Chinese characteristics and also highlighting the spirit of the Olympic Games. The grand sports event has promoted cultural exchanges everywhere.

Now the global 4.0 era is approaching, and China is meeting the greatest opportunity and 
challenge. The rapid rise of the economy has enabled China to quickly reach the center of the world stage. China has become an important force for peace and development in the world today. Through large-scale international conferences and the use of refreshing logo, the world can rediscover China. The prerequisite for the inheritance and development of local culture is the establishment of the cultural self-confidence. On the scale, China's industrial design has reached the world's leading scale and is going to break the world's leading level. China's design is emerging from plagiarizing and imitating western theories and methods and China strives to become an innovative design power, while the development of Chinese design must be based on the local culture. The local culture is the foundation for Chinese design to develop and grow and the integrating point between the local culture and internationalization must be found. The conference logo should be designed by the systematic method to optimize the conference logo as a whole. Please check the following three methods. First, the local culture should be respected ideologically and the philosophical thinking and aesthetic ideals in local culture should be dug deeply. It is necessary to introduce deep-thinking cultural connotations to understand, digest, and regenerate local cultures. The oriental way of thinking should be broadened and the thought essence of the local cultures should be absorbed. The theme of international conferences is focused on to look for the expressions to prominent themes; second, the local culture is integrated with foreign cultures and the traditional art should be combined with modern art perfectly. The essence of the traditional art is absorbed and the artistic expression of logo design is enriched to make the innovative design with oriental features. Aiming at different conference themes, the logo which accords with the conference is designed. The appropriate simplifications and optimizations should be done. Third, the modern digital technology should be made full use of, so that the logo has a sense of fashion. Advanced scientific and technological means should be introduced in China's design and the digital technology should be used to reinterpret the patterns and symbols of the local culture. In order to rejuvenate the traditional art, make it more dynamic with the times, and meet the modern aesthetic tastes and pay attention to the audience's feelings, the designers should have the internet thinking. The above-mentioned several representative logos and the novel logos created by the drawing software have the characteristics of the new era, accurately express the theme of each conference, and have attracted the attention of people all over the world to make people commit to memory and leave a deep impression on people. These logos are not only the carriers for the local cultures to go to the world, but also the media for people of all countries to communicate with each other and convey information. It also demonstrates the determination of the Chinese people to build a beautiful homeland for common global development while realizing the Chinese dream. In short, the logo design of large-scale international conferences is inseparable from the nourishment of the local culture. The reference to local cultural elements has increased the creativity and cultural connotation of logo patterns, making logo design more distinctive and dynamic, while the local culture gets inherited and sublimated by conference logos.

\section{References}

[1] Liu yan. Local cultural spirit interpretation of logo design[J] packaging world, 2014(03):8-9

[2] Li bin fang. Research on local culture and modern logo design, wuhan textile university, 2013.

[3] Zhang jing, wang jun. Exhibition vision [M]. Wuhan: wuhan university press, 2006.

[4] Zhu xin. The national culture and cultural characteristics of logo design [J] beauty and time, 2005(07): 49-51

[5] Wang fangfang. Application of traditional auspicious patterns in modern logo design, [J] packaging engineering, 2016(09):172-175

[6] Fu xiaolong, Yang nana. Application of Oriental traditional graphic elements in modern logo design[J] packaging engineering, 2010(11):82-88

[7] (Author unknown) (2013) The 20 biggest logo design trends. Available at: www.creativebloq.com/branding/biggest-logo-design-trends(Accessed 24/10/17) 
[8] Liu Pu, Guan Jiaqing. Three Expression Froms of Logo Design-Hyper-plane, Dynamics and Interaction. IEEE 10th International Conference on Computer-Aided Industrial Design \& Conceptual Design, 2010:1624-1627

[9] YuJuan Yao. Modern Logo Design in Chinese Traditional Patterns. Bulletin of Asian Design Culture Society: International Symposium of Asian Design Culture Society,2012(06):323-328

[10] Lili Sun. Study on the Application of Chinese Traditional Patterns in Modern Graphic Design. International Conference on Arts, Design and Contemporary Education (ICADCE 2016) 